\title{
The Effect of Body Mass Index on Long-Term Patient-Reported Outcome Scores after Anterior Cervical Discectomy and Fusion in an Asian Population: A 2-Year Study
}

\author{
Shao Jin Teo ${ }^{1}$, William Yeo ${ }^{2}$, Marcus Zhixing Ling ${ }^{1}$, Poh Ling Fong ${ }^{1}$, \\ Chang Ming Guo ${ }^{1}$, John Li Tat Chen ${ }^{1}$, Reuben Chee Cheong Soh ${ }^{1}$ \\ ${ }^{1}$ Department of Orthopaedic Surgery, Singapore General Hospital, Singapore \\ ${ }^{2}$ Orthopaedic Diagnostic Center, Singapore General Hospital, Singapore
}

Study Design: Retrospective cohort study.

Purpose: This study aims to analyze the relationship between body mass index (BMI) subjective patient-reported outcomes (PRO) after 1- and 2-level anterior cervical discectomy and fusion (ACDF).

Overview of Literature: The prevalence of cervical spondylosis and ACDF in expected to continue rising among the aging population of Asia. Moreover, the prevalence of obesity is also increasing. However, limited information is available about the mechanism by which BMI affects PRO after ACDF.

Methods: Total 878 patients underwent ACDF between 2000 and 2015. After excluding patients with previous cervical instrumentation, >2 levels fused, missing BMI measurement, or neoplastic/trauma indication for surgery, 535 patients were included. The PRO measures of the Neck Disability Index, Numerical Pain Rating Scale (NPRS) for Neck Pain, NPRS for Limb Pain, American Academy of Orthopaedic Surgeons-Neurogenic Symptom Score, and Japanese Orthopaedic Association myelopathy score were used. Patients were grouped based on their preoperative BMI, as per the World Health Organization guidelines for Asian populations. PRO scores were collected preoperatively, at 6 months postoperatively, and 2 years postoperatively. A generalized linear model was used to analyze the relationship of BMI category with the individual score, accounting for several factors that are likely to affect the outcomes. Results: Total 19 (3.4\%) were underweight, $155(28.0 \%)$ were normal weight, $112(20.3 \%)$ were overweight, and 267 (48.3\%) were obese. Patients across all BMI categories experienced significant and similar improvements in their postoperative PRO scores. There were no significant differences in the preoperative, 6-month postoperative, and 2-year postoperative PRO scores of the groups. Rate of reoperation was highest in patients with grade II obesity at $8.07 \%$; however, the difference was not statistically significant. Conclusions: Irrespective of the BMI, all patients exhibited similar satisfactory outcomes following ACDF. The results support surgery in all subgroups of patients with symptomatic nerve compression in the cervical spine.

Keywords: Spine surgery; Spinal fusion; Multivariate analysis; Treatment outcome; Body mass index; Obesity

Received Jan 11, 2020; Revised Feb 16, 2020; Accepted Mar 18, 2020

Corresponding author: Shao Jin Teo

Department of Orthopaedic Surgery, Singapore General Hospital, Outram Road, Singapore 169608

Tel: +65-96221213, Fax: +65-62927463, E-mail: shaojin.teo@mohh.com.sg 


\section{Introduction}

Anterior cervical discectomy and fusion (ACDF) is currently regarded as the gold standard for the treatment of cervical radiculopathy and myelopathy, especially in the context of cervical spondylosis. With a rapidly ageing global population, the prevalence of spondylosis and the need for ACDF is expected to increase. Along with age, the prevalence of obesity is also on the rise in the global population. In 2014, the reported global prevalence of obesity was 30\%, affecting 2.1 billion people. These trends underscore the importance of understanding the role of body mass index (BMI) in affecting the outcomes of ACDF [1].

Multiple studies have shown that obese patients have higher rates of complications, readmissions, reoperations, as well as higher costs in spinal fusion surgeries and elective spinal surgeries in general [2-7]. In 2016, Higgins et al. [2] reported that there was an increased rate of deep surgical site infections and major medical complications including stroke, myocardial infarction, and acute kidney injury in obese patients after spinal fusion surgeries. However, to our knowledge, detailed examination of the subjective patient-reported outcome scores (PROS) has not been conducted in the context of ACDF. Our research question was: Does BMI affect patient satisfaction and quality of life, as measured by PROS, in the context of ACDF?

The authors hypothesize that patients belonging to the two ends of the BMI spectrum may exhibit poorer PROS after ACDF because of both surgical and non-surgical factors. Obese patients may require longer operating time with greater degree of soft tissue dissection and longer periods of immobility. They also have a greater burden of comorbidities that may prevent them from fully benefitting from the ACDF. Furthermore, obesity is also linked to lower socioeconomic status in developed economies that is itself linked to poorer outcomes in many surgical procedures [8]. In contrast, in underweight, malnourishment, and nutritional deficiency are known factors that contribute to poor wound healing and longer recovery periods.

Previous studies on the predictors of ACDF outcomes have also identified positive predictors, such as young age, shorter duration of symptoms, isolated radicular pain, male sex, and a low preoperative Neck Disability Index (NDI) score $[9,10]$. However, few studies have included $\mathrm{BMI}$ and those that had included BMI compared the obese group against the normal-weight group. This was based on the hypothesis that any inferior outcome would be in the obese groups. In addition, existing studies have analyzed only the Western population, wherein BMI, comorbidity, and patient characteristics differ significantly from those in Asian populations. This study aimed to study the impact of BMI on the PROS after ACDF in an Asian population and determine if BMI should be considered while performing ACDF for patients.

\section{Materials and Methods}

This retrospective cohort study was based on a prospectively collected database maintained by a team of trained physiotherapists. Patients were independently assessed by the team preoperatively and then at 6 months and 2 years postoperatively. Patient progress was tracked through the relevant scoring systems, and measurements were taken at each assessment. Total 878 patients were identified to have undergone an ACDF in the 15-year period between 2002 and 2017. As per the inclusion criteria, patients aged $>18$ years who had undergone one- or two-level ACDF for radiculopathy, myelopathy, or myeloradiculopathy were included. As per the exclusion criteria, patients with missing data; those lost to follow-up, trauma, and malignancy; or those with a history of previous cervical spine instrumentation were excluded. Total 65 patients were first excluded because of missing BMI values. Further, 177 patients were then excluded because they did not return for follow-up at the Orthopaedic Diagnostic Center. Of these 177, 16 died because of causes unrelated to the ACDF. Total 78 patients were lost to follow-up because of unexplained non-attendance. Another 80 patients were excluded because they underwent fusion of more than two cervical segments. Finally, three patients were excluded because they had undergone previous cervical instrumentation, and the 553 remaining patients were included in this study.

This paper was exempted from the IRB approval as all data are anonymized and untraceable. For the same reason, patient consent was not required.

\section{Parameters}

Preoperative data on age, sex, weight, height, BMI, diabetes mellitus (DM), and other comorbidities were collected. We used the following scoring systems: the NDI, the American Academy of Orthopaedic Surgeons-Neu- 
rogenic Symptom Score (AAOS-NSS), and the 11-point Numerical Pain Rating Scale (NPRS) that was used for Limb Pain (NPRS-LP) and Neck Pain (NPRS-NP). The NPRS is scored on a scale ranging from $0-10$, with 0 indicating no pain and 10 indicating maximum pain. The Japanese Orthopaedic Association (JOA) score was also included for patients with myelopathy or myeloradiculopathy. Patient satisfaction was recorded as the response to the question "How would you rate the overall results of your treatment for neck or arm pain?", as adapted from Question 53 in the AAOS Cervical Instrument Questionnaire. Patients chose from a 6-point scale to indicate their level of satisfaction. All these measurements were performed preoperatively and repeated postoperatively at the 6 months and 2 years after the surgery, when the patients were again assessed by the physiotherapists.

\section{Data analyses}

$\mathrm{BMI}$ is calculated as the weight $(\mathrm{kg})$ divided by the height $\left(\mathrm{m}^{2}\right)\left(\mathrm{BMI}=\right.$ weight $/$ height $\left.^{2}\right)$. For the main purpose of this study, the Asian classification of BMI established by the World Health Organization (WHO) task force in 2002 was used. Owing to the inherent differences in body composition and risks between the Asian and Western populations, this separate BMI classification system is used in public health planning and everyday clinical practice in Asia. The categories were as follows: underweight (BMI, $<18.5 \mathrm{~kg} / \mathrm{m}^{2}$ ), normal (BMI, $18.5-22.9 \mathrm{~kg} / \mathrm{m}^{2}$ ), overweight (BMI, 23-24.9 kg/m²), obese I (BMI, $25-29.9 \mathrm{~kg} / \mathrm{m}^{2}$ ), and obese II (BMI, $>30 \mathrm{~kg} / \mathrm{m}^{2}$ ). In addition, we performed an analysis based on the WHO classification of BMI categories to allow a comparison with the existing literature that have used the WHO classification. The WHO BMI categories are underweight $\left(\mathrm{BMI},<18.5 \mathrm{~kg} / \mathrm{m}^{2}\right.$ ), normal (BMI, $18.5-24.9 \mathrm{~kg} / \mathrm{m}^{2}$ ), overweight (BMI, $25-29.9 \mathrm{~kg} / \mathrm{m}^{2}$ ), and obese (BMI, $>30 \mathrm{~kg} / \mathrm{m}^{2}$ ). Subdivision of the WHO obese category was not possible due to the small sample size.

A further subgroup analysis was performed, examining one-level and two-level ACDF separately, using the Asian BMI classification. For the subgroup analysis, the obese I and obese II groups are merged into the obese group.

Baseline patient characteristics were analyzed with the Student $t$-test for continuous variables and Pearson chisquare for categorical variables. Outcome variables and PROS were analyzed using a general linear model to assess the significant differences between the BMI groups.
The models were adjusted for age, sex, smoking status, depression, and DM. All the statistical analyses were performed using IBM SPSS Statistics for Macintosh ver. 24.0 (IBM Corp., Armonk, NY, USA). The level of significance was set at 0.05 .

\section{Results}

Of the 553 patients, 19 (3.4\%) were underweight, 155 (28.0\%) were normal weight, $112(20.3 \%)$ were overweight, and 267 (48.3\%) were obese. Of the obese group, $205(37.1 \%)$ were in obese-I category and $62(11.2 \%)$ were in obese-II category. The mean BMI was $25.2 \pm 4.42 \mathrm{~kg} / \mathrm{m}^{2}$, ranging from $14.03-52.59 \mathrm{~kg} / \mathrm{m}^{2}$. Only five patients had BMI $>40 \mathrm{~kg} / \mathrm{m}^{2}$. The mean age was $54.0 \pm 10.5$ years. There were no significant differences among the four categories in terms of age, sex, smoking status, depression, or proportion of myelopathy cases. DM was significantly associated with higher BMI categories $(p \leq 0.001)$, in line with the known epidemiology of DM. The patient demography is further detailed in Table 1.

Reflecting the focus of this paper on an Asian population, of the 553 patients, 468 (84.6\%) were Chinese, 32 (5.79\%) were Indian, and $42(7.59 \%)$ were Malay. The remaining $11(1.99 \%)$ included a mix of Eurasian and Caucasian patients. This is reflective of the general resident population of Singapore, with 74.3\% Chinese, 9.0\% Indians, $13.4 \%$ Malay, and 3.3\% other subjects.

\section{Patient-reported outcome scores}

The result of our multivariate analysis, after adjusting for gender, sex, smoking status, depression, and DM revealed that patients across all five BMI categories experienced similar levels of improvements in their postoperative PROS. There were no significant differences among the groups in any of the preoperative as well as 6-month and 2-year postoperative PROS (Table 1). Performing the analysis using the WHO BMI classification also provided same findings in the four BMI categories (Table 2).

\section{Length of procedure and stay}

Length of procedure and stay were analyzed using univariate analyzed, and no significant differences were found among the five groups. 
Table 1. Patient demographics and analysis by Asian body mass index categories

\begin{tabular}{|c|c|c|c|c|c|c|c|}
\hline Characteristic & $\begin{array}{l}\text { Underweight } \\
\qquad(\mathrm{N}=19)\end{array}$ & $\begin{array}{l}\text { Normal weight } \\
\quad(\mathrm{N}=155)\end{array}$ & $\begin{array}{l}\text { Overweight } \\
(\mathrm{N}=112)\end{array}$ & $\begin{array}{l}\text { Obese I } \\
(\mathrm{N}=205)\end{array}$ & $\begin{array}{l}\text { Obese II } \\
(\mathrm{N}=62)\end{array}$ & Power & $p$-value \\
\hline Age (yr) & $58.58 \pm 9.59$ & $54.83 \pm 11.03$ & $53.77 \pm 9.03$ & $54.04 \pm 10.17$ & $51.99 \pm 10.62$ & - & 0.128 \\
\hline Gender & & & & & & - & 0.056 \\
\hline Male & 10 & 71 & 65 & 126 & 34 & & \\
\hline Female & 9 & 84 & 47 & 79 & 28 & - & \\
\hline Diabetes & 0 & 17 & 12 & 42 & 18 & - & 0.001 \\
\hline Ischemic heart disease & 1 & 1 & 6 & 18 & 6 & 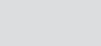 & 0.013 \\
\hline Arthritis & 4 & 13 & 10 & 23 & 5 & & 0.436 \\
\hline Depressive disorder & 1 & 6 & 2 & 4 & 2 & 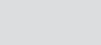 & 0.708 \\
\hline Smoking & 11 & 111 & 90 & 156 & 51 & - & 0.112 \\
\hline Depression & 1 & 6 & 2 & 4 & 2 & - & 0.711 \\
\hline Length of stay (day) & $4.86 \pm 5.93$ & $3.93 \pm 6.53$ & $3.03 \pm 1.84$ & $3.00 \pm 1.90$ & $3.54 \pm 4.27$ & - & 0.172 \\
\hline Length of procedure (min) & $135.47 \pm 38.64$ & $134.53 \pm 75.74$ & $128.47 \pm 42.55$ & $128.61 \pm 36.04$ & $140.81 \pm 55.82$ & - & 0.575 \\
\hline Myelopathy/myeloradiculopathy & $13(68.4)$ & $82(52.9)$ & $59(52.7)$ & $104(50.7)$ & $39(62.9)$ & - & 0.333 \\
\hline Level fused & & & & & & - & 0.262 \\
\hline One & $8(42.1)$ & $83(53.5)$ & $56(50.0)$ & $98(47.8)$ & $23(37.1)$ & & \\
\hline Two & $11(57.9)$ & $72(46.5)$ & $56(50.0)$ & $107(52.2)$ & $39(62.9)$ & & \\
\hline \multicolumn{8}{|l|}{ NDI } \\
\hline Preop & $38.54 \pm 23.94$ & $35.67 \pm 21.65$ & $31.33 \pm 20.32$ & $33.07 \pm 19.74$ & $36.50 \pm 20.91$ & 0.224 & 0.623 \\
\hline $6 \mathrm{mo}$ & $10.69 \pm 8.91$ & $18.31 \pm 18.41$ & $11.61 \pm 11.34$ & $15.76 \pm 15.34$ & $15.72 \pm 15.45$ & 0.616 & 0.063 \\
\hline $2 \mathrm{yr}$ & $15.00 \pm 18.83$ & $14.11 \pm 16.77$ & $8.90 \pm 11.02$ & $13.61 \pm 16.43$ & $14.00 \pm 16.26$ & 0.616 & 0.183 \\
\hline \multicolumn{8}{|l|}{ AAOS-NSS } \\
\hline Preop & $45.96 \pm 28.64$ & $51.06 \pm 26.72$ & $49.38 \pm 27.18$ & $51.05 \pm 26.50$ & $52.31 \pm 24.25$ & 0.100 & 0.940 \\
\hline $6 \mathrm{mo}$ & $15.09 \pm 18.74$ & $15.09 \pm 18.74$ & $17.83 \pm 21.66$ & $19.15 \pm 23.26$ & $15.05 \pm 20.47$ & 0.454 & 0.155 \\
\hline $2 \mathrm{yr}$ & $13.82 \pm 17.95$ & $18.14 \pm 22.71$ & $16.68 \pm 21.66$ & $17.42 \pm 23.55$ & $19.89 \pm 22.98$ & 0.175 & 0.865 \\
\hline \multicolumn{8}{|l|}{ NPRS-LP } \\
\hline Preop & $3.79 \pm 3.97$ & $3.83 \pm 3.63$ & $3.73 \pm 3.55$ & $4.15 \pm 3.58$ & $4.16 \pm 3.55$ & 0.204 & 0.729 \\
\hline $6 \mathrm{mo}$ & $0.90 \pm 2.38$ & $1.23 \pm 2.31$ & $1.00 \pm 2.00$ & $1.17 \pm 2.32$ & $0.97 \pm 1.97$ & 0.087 & 0.877 \\
\hline $2 \mathrm{yr}$ & $0.42 \pm 1.31$ & $1.04 \pm 2.31$ & $0.77 \pm 1.99$ & $1.13 \pm 2.49$ & $1.16 \pm 2.25$ & 0.293 & 0.577 \\
\hline \multicolumn{8}{|l|}{ NPRS-NP } \\
\hline Preop & $3.90 \pm 3.43$ & $4.85 \pm 3.23$ & $4.32 \pm 3.21$ & $4.58 \pm 3.31$ & $4.37 \pm 3.48$ & 0.197 & 0.636 \\
\hline $6 \mathrm{mo}$ & $0.79 \pm 1.96$ & $1.67 \pm 2.63$ & $1.18 \pm 2.31$ & $1.91 \pm 2.77$ & $1.45 \pm 2.67$ & 0.575 & 0.071 \\
\hline $2 \mathrm{yr}$ & $0.95 \pm 2.15$ & $1.55 \pm 2.68$ & $1.10 \pm 2.27$ & $1.60 \pm 2.71$ & $1.52 \pm 2.65$ & 0.391 & 0.436 \\
\hline \multicolumn{8}{|l|}{$\mathrm{JOA}$} \\
\hline Preop & $12.25 \pm 3.79$ & $11.41 \pm 3.37$ & $12.81 \pm 2.84$ & $12.23 \pm 2.91$ & $11.51 \pm 3.77$ & 0.709 & 0.066 \\
\hline $6 \mathrm{mo}$ & $14.60 \pm 2.19$ & $13.96 \pm 2.97$ & $15.15 \pm 2.10$ & $14.54 \pm 2.60$ & $14.82 \pm 2.62$ & 0.673 & 0.070 \\
\hline $2 \mathrm{yr}$ & $15.00 \pm 2.58$ & $14.38 \pm 2.98$ & $15.41 \pm 2.03$ & $14.77 \pm 2.42$ & $14.49 \pm 2.81$ & 0.715 & 0.099 \\
\hline \multicolumn{8}{|c|}{ AAOS-53 (no. of patients who answered 'poor' or 'terrible') } \\
\hline $6 \mathrm{mo}$ & 2 & 9 & 2 & 17 & 4 & & 0.199 \\
\hline $2 \mathrm{yr}$ & 2 & 9 & 5 & 17 & 3 & & 0.600 \\
\hline \multicolumn{8}{|l|}{ Change in NDI } \\
\hline $6 \mathrm{mo}$ & $19.05 \pm 25.02$ & $14.89 \pm 22.07$ & $17.15 \pm 20.07$ & $14.98 \pm 17.72$ & $17.08 \pm 22.72$ & 0.167 & 0.723 \\
\hline
\end{tabular}




\begin{tabular}{|c|c|c|c|c|c|c|c|}
\hline Characteristic & $\begin{array}{c}\text { Underweight } \\
(\mathrm{N}=19)\end{array}$ & $\begin{array}{l}\text { Normal weight } \\
\quad(N=155)\end{array}$ & $\begin{array}{l}\text { Overweight } \\
(\mathrm{N}=112)\end{array}$ & $\begin{array}{l}\text { Obese I } \\
\text { (N=205) }\end{array}$ & $\begin{array}{c}\text { Obese II } \\
(\mathrm{N}=62)\end{array}$ & Power & $p$-value \\
\hline $2 \mathrm{yr}$ & $15.32 \pm 27.41$ & $18.09 \pm 22.88$ & $19.46 \pm 20.49$ & $16.95 \pm 20.42$ & $18.69 \pm 22.89$ & 0.148 & 0.837 \\
\hline \multicolumn{8}{|c|}{ Change in AAOS-NSS } \\
\hline $6 \mathrm{mo}$ & $30.88 \pm 30.10$ & $28.65 \pm 27.98$ & $31.55 \pm 26.38$ & $31.90 \pm 27.94$ & $37.26 \pm 29.37$ & 0.417 & 0.281 \\
\hline $2 \mathrm{yr}$ & $32.14 \pm 27.00$ & $32.92 \pm 31.06$ & $32.70 \pm 27.52$ & $33.63 \pm 27.59$ & $32.42 \pm 30.68$ & 0.120 & 0.984 \\
\hline \multicolumn{8}{|c|}{ Change in NPRS-LP } \\
\hline $6 \mathrm{mo}$ & $2.90 \pm 3.94$ & $2.60 \pm 3.50$ & $2.73 \pm 3.40$ & $2.97 \pm 3.51$ & $3.19 \pm 3.64$ & 0.226 & 0.865 \\
\hline $2 \mathrm{yr}$ & $3.37 \pm 3.53$ & $2.79 \pm 3.85$ & $2.96 \pm 3.46$ & $3.02 \pm 3.62$ & $3.00 \pm 3.63$ & 0.136 & 0.668 \\
\hline \multicolumn{8}{|c|}{ Change in NPRS-NP } \\
\hline $6 \mathrm{mo}$ & $3.11 \pm 3.30$ & $3.18 \pm 3.28$ & $3.14 \pm 3.51$ & $2.67 \pm 3.60$ & $2.92 \pm 3.50$ & 0.110 & 0.810 \\
\hline $2 \mathrm{yr}$ & $2.95 \pm 3.32$ & $3.31 \pm 3.54$ & $3.22 \pm 3.29$ & $2.98 \pm 3.64$ & $2.86 \pm 3.51$ & 0.106 & 0.939 \\
\hline \multicolumn{8}{|l|}{ Change in JOA } \\
\hline $6 \mathrm{mo}$ & $1.74 \pm 2.65$ & $1.58 \pm 3.57$ & $1.50 \pm 2.54$ & $1.40 \pm 2.92$ & $2.35 \pm 3.38$ & 0.418 & 0.338 \\
\hline $2 y r$ & $2.03 \pm 3.72$ & $1.68 \pm 4.28$ & $1.26 \pm 3.74$ & $1.41 \pm 3.83$ & $2.35 \pm 3.31$ & 0.338 & 0.434 \\
\hline
\end{tabular}

Values are presented as mean \pm standard deviation, number, or number $(\%)$.

Preop, preoperative; NDI, Neck Disability Index; AAOS-NSS, American Academy of Orthopaedic Surgeons-Neurogenic Symptom Score; NPRS-LP, Numerical Pain Rating Scale for Limb Pain; NPRS-NP, Numerical Pain Rating Scale for Neck Pain; JOA, Japanese Orthopaedic Association.

\section{Rates of reoperation}

Of the 553 patients, $26(4.70 \%)$ subsequently underwent reoperation of the cervical spine. Twenty-four patients underwent another ACDF because of adjacent segment disease, while the remaining two underwent posterior revision surgery because of recurrent instability at the original fused segments. Comparing the rates of reoperation across the BMI categories showed that the rate was highest in the obese-II category subjects (5 [8.07\%]). However, chi-square test revealed that the difference in the reoperation rates was not significant (Table 3).

\section{Subgroup analyses}

A multivariate subgroup analysis was performed on onelevel and two-level ACDFs separately. In the one-level analysis, all four BMI categories were associated with similar levels of improvement after surgery. They also achieved similar levels of PROS at 6 months and 2 years postoperatively (Table 4).

In the two-level analysis, it is observed that at 6 months after the surgery, the overweight group had significantly better NDI $(p=0.012)$, JOA $(p=0.019)$, and NPRS-NP $(p=0.047)$ scores than the other groups. However, there were no differences in the postoperative degree of im- provement among the four groups (Table 5).

\section{Discussion}

The choice of PROM in this study is based on previous research that has proven the validity and reliability of these PROS [11]. With the use of PROS, the minimum clinically important difference (MCID) has to be defined. In this study, the MCID for NDI was set at 16 and JOA at 1 , based on past validation studies $[12,13]$. The use of multiple PROS allows for more complete assessment of the outcome. While the NPRS focuses on the assessment of pain, the NDI has a larger focus on the daily functions and quality of life.

This study was conducted for multiple reasons. First, while many studies have shown that perioperative complications were more common in obese subjects after ACDF, only one study has examined the impact of obesity on PROS after ACDF [14]. However, this study by Sielatycki et al. [14] enrolled fewer subjects (299 patients) and had a shorter follow-up period of 1 year. The impact of BMI on long-term patient-reported outcomes in ACDF remains unclear. There is an increasing recognition of the importance of PROS as a measure of successful and meaningful treatment because these scores are designed to assess the actual quality of life and satisfaction, rather than only 
Table 2. Analysis by the World Health Organization body mass index categories

$\mathrm{NDI}$

\begin{tabular}{|c|c|c|c|c|c|}
\hline Preop & $38.54 \pm 23.94$ & $33.84 \pm 21.16$ & $33.07 \pm 19.74$ & $36.50 \pm 20.91$ & 0.643 \\
\hline $6 \mathrm{mo}$ & $10.69 \pm 8.91$ & $15.47 \pm 16.13$ & $15.76 \pm 15.34$ & $15.72 \pm 15.45$ & 0.622 \\
\hline $2 y r$ & $15.00 \pm 18.83$ & $11.94 \pm 14.85$ & $13.61 \pm 16.43$ & $14.00 \pm 16.26$ & 0.559 \\
\hline \multicolumn{6}{|c|}{ AAOS-NSS } \\
\hline Preop & $45.96 \pm 28.64$ & $50.35 \pm 26.88$ & $51.05 \pm 26.50$ & $52.31 \pm 24.25$ & 0.854 \\
\hline $6 \mathrm{mo}$ & $15.09 \pm 18.74$ & $20.48 \pm 23.38$ & $19.15 \pm 23.26$ & $15.05 \pm 20.47$ & 0.182 \\
\hline $2 y r$ & $13.82 \pm 17.95$ & $17.53 \pm 22.25$ & $17.42 \pm 23.55$ & $19.89 \pm 22.98$ & 0.744 \\
\hline \multicolumn{6}{|l|}{ NPRS-LP } \\
\hline Preop & $3.79 \pm 3.97$ & $3.79 \pm 3.59$ & $4.15 \pm 3.58$ & $4.16 \pm 3.55$ & 0.570 \\
\hline $6 \mathrm{mo}$ & $0.90 \pm 2.38$ & $1.14 \pm 2.18$ & $1.17 \pm 2.32$ & $0.97 \pm 1.97$ & 0.832 \\
\hline $2 y r$ & $0.42 \pm 1.31$ & $0.93 \pm 2.18$ & $1.13 \pm 2.49$ & $1.16 \pm 2.25$ & 0.468 \\
\hline \multicolumn{6}{|l|}{ NPRS-NP } \\
\hline Preop & $3.90 \pm 3.43$ & $4.63 \pm 3.23$ & $4.58 \pm 3.31$ & $4.37 \pm 3.48$ & 0.737 \\
\hline $6 \mathrm{mo}$ & $0.79 \pm 1.96$ & $1.47 \pm 2.51$ & $1.91 \pm 2.77$ & $1.45 \pm 2.67$ & 0.071 \\
\hline $2 y r$ & $0.95 \pm 2.15$ & $1.36 \pm 2.52$ & $1.60 \pm 2.71$ & $1.52 \pm 2.65$ & 0.485 \\
\hline \multicolumn{6}{|l|}{ JOA } \\
\hline Preop & $12.25 \pm 3.79$ & $11.98 \pm 3.23$ & $12.23 \pm 2.90$ & $11.51 \pm 3.77$ & 0.285 \\
\hline $6 \mathrm{mo}$ & $14.60 \pm 2.19$ & $14.45 \pm 2.71$ & $14.54 \pm 2.60$ & $14.82 \pm 2.62$ & 0.654 \\
\hline $2 \mathrm{yr}$ & $15.00 \pm 2.58$ & $14.79 \pm 2.68$ & $14.77 \pm 2.42$ & $14.49 \pm 2.81$ & 0.494 \\
\hline \multicolumn{6}{|c|}{ AAOS-53 (no. of patients who answered 'poor' or 'terrible') } \\
\hline $6 \mathrm{mo}$ & 2 & 11 & 17 & 4 & 0.243 \\
\hline $2 y r$ & 2 & 14 & 17 & 3 & 0.464 \\
\hline \multicolumn{6}{|l|}{$\mathrm{NDI}$} \\
\hline $6 \mathrm{mo}$ & $19.05 \pm 25.02$ & $15.84 \pm 21.25$ & $14.98 \pm 17.72$ & $17.08 \pm 22.72$ & 0.824 \\
\hline $2 y r$ & $15.32 \pm 27.41$ & $18.67 \pm 21.88$ & $16.95 \pm 20.42$ & $18.69 \pm 22.89$ & 0.828 \\
\hline \multicolumn{6}{|c|}{ AAOS-NSS } \\
\hline $6 \mathrm{mo}$ & $30.88 \pm 30.10$ & $29.87 \pm 27.30$ & $31.90 \pm 27.94$ & $37.26 \pm 29.37$ & 0.254 \\
\hline $2 \mathrm{yr}$ & $32.14 \pm 27.00$ & $32.82 \pm 29.58$ & $33.63 \pm 27.59$ & $32.42 \pm 30.68$ & 0.945 \\
\hline \multicolumn{6}{|l|}{ NPRS-LP } \\
\hline $6 \mathrm{mo}$ & $2.90 \pm 3.94$ & $2.65 \pm 3.45$ & $2.97 \pm 3.51$ & $3.19 \pm 3.64$ & 0.553 \\
\hline $2 y r$ & $3.37 \pm 3.53$ & $2.86 \pm 3.69$ & $3.02 \pm 3.62$ & $3.00 \pm 3.63$ & 0.800 \\
\hline \multicolumn{6}{|l|}{ NPRS-NP } \\
\hline $6 \mathrm{mo}$ & $3.11 \pm 3.30$ & $3.16 \pm 3.37$ & $2.67 \pm 3.60$ & $2.92 \pm 3.50$ & 0.663 \\
\hline $2 \mathrm{yr}$ & $2.95 \pm 3.32$ & $3.27 \pm 3.43$ & $2.98 \pm 3.64$ & $2.86 \pm 3.51$ & 0.858 \\
\hline \multicolumn{6}{|l|}{ JOA } \\
\hline $6 \mathrm{mo}$ & $1.74 \pm 2.65$ & $1.55 \pm 3.17$ & $1.40 \pm 2.92$ & $2.35 \pm 3.38$ & 0.209 \\
\hline $2 y r$ & $2.03 \pm 3.72$ & $1.50 \pm 4.06$ & $1.41 \pm 3.83$ & $2.35 \pm 3.31$ & 0.335 \\
\hline
\end{tabular}

Values are presented as mean \pm standard deviation.

NDI, Neck Disability Index; Preop, preoperative; AAOS-NSS, American Academy of Orthopaedic Surgeons-Neurogenic Symptom Score; NPRS-LP, Numerical Pain Rating Scale for Limb Pain; NPRS-NP, Numerical Pain Rating Scale for Neck Pain; JOA, Japanese Orthopaedic Association. 
Table 3. Reoperation rates

$\begin{array}{ccccccc} & \text { Underweight }(\mathrm{N}=19) & \text { Normal weight }(\mathrm{N}=155) & \text { Overweight }(\mathrm{N}=112) & \text { Obese I ( } \mathrm{N}=205) & \text { Obese II (N=62) } & p \text {-value }\end{array}$

Values are presented as number (\%).

clinical symptoms.

Moreover, previous studies on ACDF and its relationship with BMI have noted a close association between increasing BMI and poorer objective outcomes $[2,4,6]$. However, we disagree with this, given our experience with the Singaporean population, with marginal increase in the reoperation rates across various BMI groups as an example. One possible reason for this is the association of lower BMI with osteoporosis [15].

Second, most studies, including the one study mentioned earlier, were performed on Western populations. The results of these studies may not be applicable to Asian populations owing to the known differences in BMI, body proportion, and body composition. For example, in the study by Sielatycki et al. [14], 26.8\% of the patients had a BMI $>35 \mathrm{~kg} / \mathrm{m}^{2}$, compared to a mere $2.9 \%$ in our study sample. Even in the same BMI range, Asian individuals had a very different risk profile than Western individuals for many BMI-related conditions [16]. At the same time, the Asian population is experiencing a steady increase in the obesity rates. Hence, there is an actual need for a study that examines the relationship between BMI and PROS in an Asian population.

Finally, many studies have limited themselves to comparing obese patients against normal-weight patients. This is based on the hypothesis that only obese subjects experienced inferior outcomes. However, we believe that underweight patients may be at higher risk of poorer outcomes because of reasons, such as malnutrition, underlying comorbidities, and smaller cervical spinal muscle mass. Hence, in this study, we compared the five BMI categories, rather than simplify the comparison to obese and nonobese groups.

The mix of PROS that were utilized in this study encompassed three main areas-neck pain, neurogenic pain, and function. The results show that no BMI category experienced statistically or clinically different PROS than other BMI groups. Moreover, all five BMI groups exhibited similar levels of improvement in their PROS. The results suggest that in our population, patients across all BMI subgroups can expect to experience meaning- ful symptom reduction following ACDF. Moreover, the degree of benefit is comparable across BMI groups. Our results give clinicians the confidence to correctly counsel patients for ACDF, irrespective of their BMI. However, the authors would like to stress that obese patients should still be counseled on the numerous other general health benefits of weight loss. In addition, several studies have found obesity to be significantly associated with neck and lower back pain [17].

Many other studies have investigated the impact of obesity on other spine surgeries. Seicean et al. [18] looked at the impact of BMI on the objective outcomes on elective spinal surgery in general. They found that after propensity matching, patients with BMI $>40 \mathrm{~kg} / \mathrm{m}^{2}$ had increased odds of complications, readmissions, and reoperations. Kalanithi et al. [6] found that morbid obesity (BMI $>40$ $\mathrm{kg} / \mathrm{m}^{2}$ ) is associated with higher in-hospital complications, mortality, and costs in spinal fusion surgeries. Schoenfeld et al. [19], in a large prognostic study, found that increasing BMI was associated with complications, although the association was much stronger with minor complications rather than with major complications. Conversely, Buerba et al. [20] found that obesity was not associated with greater incidence of postoperative complications in their study examining anterior and posterior cervical fusions. Based on these other studies, it appears that the risks of perioperative complications increase significantly in morbidly obese patients with $\mathrm{BMI}>40 \mathrm{~kg} / \mathrm{m}^{2}$, while those with lower grades of obesity (BMI $<40 \mathrm{~kg} / \mathrm{m}^{2}$ ) do not have significantly higher risks. With this study, it is evident that subjective outcomes, in the form of PROM scores, are not compromised in those with lower grades of obesity.

Our results revealed that while the obese II group had the highest reoperative risk at $8.07 \%$, the difference was not significant $(p=0.453)$. This is in contrast to some reports that had found greater risk of reoperation in morbidly obese patients with $\mathrm{BMI}>40 \mathrm{~kg} / \mathrm{m}^{2}$. However, in the author's experience, extremes of BMI, both high and low, are often associated with significant comorbidities and mortality that would preclude patients from undergoing revision surgery even if clinically warranted. Thus, the 
Table 4. One-level subanalysis

\begin{tabular}{|c|c|c|c|c|c|}
\hline Variable & Underweight (N=8) & Normal weight (N=83) & Overweight (N=56) & Obese (N=120) & $p$-value \\
\hline \multicolumn{6}{|l|}{ NDI } \\
\hline Preop & $35.00 \pm 19.20$ & $36.63 \pm 22.32$ & $33.52 \pm 20.63$ & $38.70 \pm 19.04$ & 0.554 \\
\hline $6 \mathrm{mo}$ & $8.20 \pm 5.89$ & $17.38 \pm 19.21$ & $13.71 \pm 13.53$ & $17.88 \pm 16.46$ & 0.366 \\
\hline $2 \mathrm{yr}$ & $17.50 \pm 21.08$ & $12.34 \pm 15.49$ & $9.76 \pm 11.38$ & $15.05 \pm 17.31$ & 0.194 \\
\hline \multicolumn{6}{|c|}{ AAOS-NSS } \\
\hline Preop & $48.33 \pm 27.20$ & $53.73 \pm 28.05$ & $55.37 \pm 27.14$ & $54.76 \pm 25.00$ & 0.837 \\
\hline $6 \mathrm{mo}$ & $15.42 \pm 19.67$ & $22.25 \pm 25.48$ & $19.17 \pm 24.23$ & $21.27 \pm 24.96$ & 0.886 \\
\hline $2 \mathrm{yr}$ & $13.33 \pm 13.80$ & $14.70 \pm 23.12$ & $18.08 \pm 23.85$ & $19.68 \pm 24.73$ & 0.463 \\
\hline \multicolumn{6}{|l|}{ NPRS-LP } \\
\hline Preop & $3.25 \pm 3.81$ & $4.05 \pm 3.73$ & $4.25 \pm 3.47$ & $4.73 \pm 3.40$ & 0.279 \\
\hline $6 \mathrm{mo}$ & $0.88 \pm 2.47$ & $1.26 \pm 2.38$ & $1.45 \pm 2.44$ & $1.30 \pm 2.37$ & 0.860 \\
\hline $2 \mathrm{yr}$ & $0.38 \pm 1.06$ & $0.67 \pm 1.94$ & $0.98 \pm 2.28$ & $1.26 \pm 2.55$ & 0.209 \\
\hline \multicolumn{6}{|l|}{ NPRS-NP } \\
\hline Preop & $4.38 \pm 2.92$ & $4.96 \pm 3.11$ & $4.51 \pm 3.27$ & $4.94 \pm 3.31$ & 0.815 \\
\hline $6 \mathrm{mo}$ & $1.38 \pm 2.67$ & $1.62 \pm 2.53$ & $1.57 \pm 2.58$ & $1.88 \pm 2.87$ & 0.644 \\
\hline $2 y r$ & $1.25 \pm 2.82$ & $1.23 \pm 2.38$ & $1.25 \pm 2.52$ & $1.78 \pm 2.79$ & 0.231 \\
\hline \multicolumn{6}{|l|}{ JOA } \\
\hline Preop & $11.40 \pm 4.92$ & $11.37 \pm 3.61$ & $12.44 \pm 3.02$ & $11.55 \pm 3.41$ & 0.659 \\
\hline $6 \mathrm{mn}$ & $15.00 \pm 3.14$ & $13.82 \pm 3.35$ & $14.61 \pm 2.49$ & $13.84 \pm 3.11$ & 0.624 \\
\hline $2 \mathrm{yr}$ & $15.90 \pm 1.67$ & $14.25 \pm 3.34$ & $15.16 \pm 2.23$ & $14.11 \pm 3.06$ & 0.369 \\
\hline \multicolumn{6}{|c|}{ AAOS-53 (no. of patients who answered 'poor' or 'terrible') } \\
\hline $6 \mathrm{mo}$ & 0 & 7 & 2 & 11 & 0.484 \\
\hline $2 \mathrm{yr}$ & 0 & 5 & 4 & 10 & 0.799 \\
\hline \multicolumn{6}{|c|}{ Change in NDI } \\
\hline 6 mo & $16.75 \pm 19.51$ & $16.90 \pm 22.96$ & $16.98 \pm 21.53$ & $17.31 \pm 19.35$ & 0.985 \\
\hline $2 \mathrm{yr}$ & $8.75 \pm 32.35$ & $20.77 \pm 22.46$ & $20.02 \pm 21.38$ & $19.83 \pm 21.75$ & 0.526 \\
\hline \multicolumn{6}{|c|}{ Change in AAOS-NSS } \\
\hline $6 \mathrm{mo}$ & $32.92 \pm 26.03$ & $31.49 \pm 29.91$ & $36.20 \pm 27.20$ & $33.49 \pm 29.26$ & 0.830 \\
\hline $2 y r$ & $35.00 \pm 22.75$ & $39.04 \pm 33.06$ & $37.29 \pm 28.65$ & $35.08 \pm 29.60$ & 0.914 \\
\hline \multicolumn{6}{|c|}{ Change in NPRS-LP } \\
\hline $6 \mathrm{mo}$ & $2.34 \pm 4.14$ & $2.79 \pm 3.71$ & $2.80 \pm 3.18$ & $3.43 \pm 3.72$ & 0.427 \\
\hline $2 \mathrm{yr}$ & $2.88 \pm 3.14$ & $3.37 \pm 3.93$ & $3.27 \pm 3.41$ & $3.47 \pm 3.76$ & 0.960 \\
\hline \multicolumn{6}{|c|}{ Change in NPRS-NP } \\
\hline $6 \mathrm{mo}$ & $3.00 \pm 3.12$ & $3.34 \pm 3.14$ & $2.94 \pm 4.00$ & $3.06 \pm 3.83$ & 0.903 \\
\hline $2 \mathrm{yr}$ & $3.13 \pm 3.18$ & $3.73 \pm 3.51$ & $3.26 \pm 3.47$ & $3.16 \pm 3.91$ & 0.714 \\
\hline \multicolumn{6}{|c|}{ Change in JOA } \\
\hline $6 \mathrm{mo}$ & $2.25 \pm 2.52$ & $1.46 \pm 3.44$ & $1.28 \pm 2.82$ & $1.15 \pm 2.51$ & 0.901 \\
\hline $2 y r$ & $2.81 \pm 3.55$ & $1.56 \pm 4.89$ & $1.06 \pm 4.24$ & $1.55 \pm 3.17$ & 0.761 \\
\hline
\end{tabular}

Values are presented as mean \pm standard deviation.

NDI, Neck Disability Index; Preop, preoperative; AAOS-NSS, American Academy of Orthopaedic Surgeons-Neurogenic Symptom Score; NPRS-LP, Numerical Pain Rating Scale for Limb Pain; NPRS-NP, Numerical Pain Rating Scale for Neck Pain; JOA, Japanese Orthopaedic Association. 
Table 5. Two-level subanalysis

\begin{tabular}{|c|c|c|c|c|c|}
\hline Variable & Underweight (N=11) & Normal weight (N=72) & Overweight $(\mathrm{N}=56)$ & Obese (N=147) & $p$-value \\
\hline \multicolumn{6}{|l|}{$\mathrm{NDI}$} \\
\hline Preop & $40.75 \pm 27.52$ & $34.56 \pm 20.96$ & $29.22 \pm 20.00$ & $30.04 \pm 20.01$ & 0.432 \\
\hline $6 \mathrm{mo}$ & $12.25 \pm 10.44$ & $19.34 \pm 17.59$ & $9.63 \pm 8.49$ & $14.08 \pm 14.21$ & 0.012 \\
\hline $2 \mathrm{yr}$ & $13.13 \pm 18.22$ & $16.11 \pm 18.01$ & $8.04 \pm 10.69$ & $12.64 \pm 15.55$ & 0.083 \\
\hline \multicolumn{6}{|c|}{ AAOS-NSS } \\
\hline Preop & $44.24 \pm 30.84$ & $47.97 \pm 24.95$ & $43.39 \pm 26.10$ & $48.52 \pm 26.47$ & 0.869 \\
\hline $6 \mathrm{mo}$ & $14.85 \pm 18.99$ & $22.58 \pm 23.36$ & $16.49 \pm 18.86$ & $15.66 \pm 20.33$ & 0.068 \\
\hline $2 \mathrm{yr}$ & $14.18 \pm 21.13$ & $22.11 \pm 21.72$ & $15.29 \pm 19.35$ & $16.60 \pm 22.22$ & 0.214 \\
\hline \multicolumn{6}{|l|}{ NPRS-LP } \\
\hline Preop & $4.18 \pm 4.21$ & $3.57 \pm 3.52$ & $3.21 \pm 3.60$ & $3.67 \pm 3.64$ & 0.670 \\
\hline $6 \mathrm{mo}$ & $0.91 \pm 2.43$ & $1.19 \pm 2.24$ & $0.56 \pm 1.30$ & $0.98 \pm 2.13$ & 0.385 \\
\hline $2 \mathrm{yr}$ & $0.45 \pm 1.51$ & $1.46 \pm 2.63$ & $0.55 \pm 1.64$ & $1.03 \pm 2.34$ & 0.185 \\
\hline \multicolumn{6}{|l|}{ NPRS-NP } \\
\hline Preop & $3.55 \pm 3.86$ & $4.74 \pm 3.39$ & $4.13 \pm 3.17$ & $4.20 \pm 3.35$ & 0.669 \\
\hline $6 \mathrm{mo}$ & $0.36 \pm 1.21$ & $1.74 \pm 2.75$ & $0.79 \pm 1.95$ & $1.74 \pm 2.65$ & 0.047 \\
\hline $2 \mathrm{yr}$ & $0.73 \pm 1.62$ & $1.92 \pm 2.97$ & $0.95 \pm 2.00$ & $1.42 \pm 2.60$ & 0.146 \\
\hline \multicolumn{6}{|l|}{ JOA } \\
\hline Preop & $12.72 \pm 3.25$ & $11.45 \pm 3.13$ & $13.13 \pm 2.68$ & $12.41 \pm 2.91$ & 0.135 \\
\hline $6 \mathrm{mo}$ & $14.39 \pm 1.65$ & $14.11 \pm 2.53$ & $15.62 \pm 1.60$ & $15.14 \pm 2.03$ & 0.019 \\
\hline $2 \mathrm{yr}$ & $14.50 \pm 2.94$ & $14.52 \pm 2.56$ & $15.62 \pm 1.85$ & $15.13 \pm 1.94$ & 0.220 \\
\hline \multicolumn{6}{|c|}{ AAOS-53 (no. of patients who answered 'poor' or 'terrible') } \\
\hline $6 \mathrm{mo}$ & 2 & 2 & 0 & 10 & 0.030 \\
\hline $2 \mathrm{yr}$ & 2 & 4 & 1 & 10 & 0.180 \\
\hline \multicolumn{6}{|l|}{ NDI } \\
\hline $6 \mathrm{mo}$ & $20.73 \pm 29.21$ & $12.57 \pm 20.92$ & $17.32 \pm 18.69$ & $13.95 \pm 18.59$ & 0.377 \\
\hline $2 y r$ & $20.09 \pm 23.67$ & $15.00 \pm 23.12$ & $18.91 \pm 19.73$ & $15.29 \pm 20.18$ & 0.466 \\
\hline \multicolumn{6}{|c|}{ AAOS-NSS } \\
\hline $6 \mathrm{mo}$ & $29.39 \pm 33.92$ & $25.39 \pm 25.39$ & $26.90 \pm 24.91$ & $32.85 \pm 27.60$ & 0.185 \\
\hline $2 \mathrm{yr}$ & $30.06 \pm 30.63$ & $25.86 \pm 27.14$ & $28.11 \pm 25.79$ & $31.92 \pm 27.17$ & 0.458 \\
\hline \multicolumn{6}{|l|}{ NPRS-LP } \\
\hline $6 \mathrm{mo}$ & $3.27 \pm 3.95$ & $2.38 \pm 3.24$ & $2.65 \pm 3.63$ & $2.69 \pm 3.34$ & 0.570 \\
\hline $2 \mathrm{yr}$ & $3.73 \pm 3.90$ & $2.11 \pm 3.67$ & $2.66 \pm 3.52$ & $2.64 \pm 3.46$ & 0.230 \\
\hline \multicolumn{6}{|l|}{ NPRS-NP } \\
\hline $6 \mathrm{mo}$ & $3.18 \pm 3.57$ & $3.00 \pm 3.46$ & $3.34 \pm 2.97$ & $2.46 \pm 3.33$ & 0.328 \\
\hline $2 \mathrm{yr}$ & $2.82 \pm 3.57$ & $2.82 \pm 3.53$ & $3.18 \pm 3.12$ & $2.77 \pm 3.33$ & 0.871 \\
\hline \multicolumn{6}{|l|}{ JOA } \\
\hline $6 \mathrm{mo}$ & $1.36 \pm 2.80$ & $1.72 \pm 3.72$ & $1.73 \pm 2.23$ & $2.01 \pm 3.40$ & 0.630 \\
\hline $2 y r$ & $1.46 \pm 3.91$ & $1.81 \pm 3.49$ & $1.46 \pm 3.17$ & $1.69 \pm 4.15$ & 0.780 \\
\hline
\end{tabular}

Values are presented as mean \pm standard deviation.

NDI, Neck Disability Index; Preop, preoperative; AAOS-NSS, American Academy of Orthopaedic Surgeons-Neurogenic Symptom Score; NPRS-LP, Numerical Pain Rating Scale for Limb Pain; NPRS-NP, Numerical Pain Rating Scale for Neck Pain; JOA, Japanese Orthopaedic Association. 
similar reoperation rates may mask the actual differences in the underlying rates of symptom recurrence or development of adjacent segment pathology among the BMI categories.

However, in our subgroup analysis of patients who underwent two-level ACDF, we found that overweight patients had significantly better scores for the NDI, JOA, and NPRS-NP than the normal weight group at 6 months after surgery. While this was unexpected, the differences did not meet the MCID for the respective PROS. We also noted that the overweight group had better preoperative PROS, although the differences were not significant. Additionally, there were no differences in the degree of improvement the groups after surgery. At 2 years after the surgery, there were no significant differences in the PROS.

There are several strengths of this study. First, the relatively large sample size increased the statistical power and robustness of our analysis. This also ensures good representation of the local population in Singapore that is evidently different from the population studied previously. Second, the data used in this study were collected prospectively by a physiotherapist who was well versed and competent in administering the PROS questionnaire. This ensures the reliability and validity of our results and conclusions. Lastly, the use of multiple validated PROM allows for a more holistic and comprehensive assessment of the functional outcome of the patients.

There are several potential limitations in this study. The exclusion of patients who did not undergo follow-up at the 6-month and 2-year postoperative follow-up may have caused selection bias. Patients who were well and asymptomatic may have missed the follow-up, while those who were symptomatic and required revision would be more likely to present for follow-up. This may lead to an overestimation of the rate of revision surgery and underestimation of improvements in the PROS.

In addition, there may be potential confounders that we have failed to account for, masking an underlying impact of BMI on the PROS. For example, patient socioeconomic and demographic data were not collected and could not be adjusted for in the analysis. However, these have been suggested to affect the treatment outcome in other orthopedic procedures [8]. Other potential confounders could be other medical comorbidities, including psychiatric conditions linked to BMI that could impact our PROS.

\section{Conclusions}

Irrespective of the BM, patients exhibited similar outcomes following ACDF and showed equal levels of improvements and satisfaction. The results support surgery in all the subgroups of patients with symptomatic nerve compression in the cervical spine.

\section{Conflict of Interest}

No potential conflict of interest relevant to this article was reported.

\section{References}

1. Ng M, Fleming T, Robinson M, et al. Global, regional, and national prevalence of overweight and obesity in children and adults during 1980-2013: a systematic analysis for the Global Burden of Disease Study 2013. Lancet 2014;384:766-81.

2. Higgins DM, Mallory GW, Planchard RF, et al. Understanding the impact of obesity on short-term outcomes and in-hospital costs after instrumented spinal fusion. Neurosurgery 2016;78:127-32.

3. Patel N, Bagan B, Vadera S, et al. Obesity and spine surgery: relation to perioperative complications. J Neurosurg Spine 2007;6:291-7.

4. Jackson KL 2nd, Devine JG. The effects of obesity on spine surgery: a systematic review of the literature. Global Spine J 2016;6:394-400.

5. Minhas SV, Chow I, Jenkins TJ, Dhingra B, Patel AA. Preoperative predictors of increased hospital costs in elective anterior cervical fusions: a single-institution analysis of 1,082 patients. Spine J 2015;15:841-8.

6. Kalanithi PA, Arrigo R, Boakye M. Morbid obesity increases cost and complication rates in spinal arthrodesis. Spine (Phila Pa 1976) 2012;37:982-8.

7. Narain AS, Hijji FY, Haws BE, et al. Impact of body mass index on surgical outcomes, narcotics consumption, and hospital costs following anterior cervical discectomy and fusion. J Neurosurg Spine 2018;28:160-6.

8. Ellis HB, Howard KJ, Khaleel M. Influence of socioeconomic status on outcome of joint replacement surgery. Curr Orthop Pract 2010;21:132-7.

9. Eriksen EF, Buhl M, Fode K, et al. Treatment of cervical disc disease using Cloward's technique: the 
prognostic value of clinical preoperative data in 1,106 patients. Acta Neurochir (Wien) 1984;70:181-97.

10. Peolsson A, Hedlund R, Vavruch L, Oberg B. Predictive factors for the outcome of anterior cervical decompression and fusion. Eur Spine J 2003;12:274-80.

11. Vernon H, Mior S. The Neck Disability Index: a study of reliability and validity. J Manipulative Physiol Ther 1991;14:409-15.

12. Parker SL, Godil SS, Shau DN, Mendenhall SK, McGirt MJ. Assessment of the minimum clinically important difference in pain, disability, and quality of life after anterior cervical discectomy and fusion: clinical article. J Neurosurg Spine 2013;18:154-60.

13. Tetreault L, Nouri A, Kopjar B, Cote P, Fehlings MG. The minimum clinically important difference of the modified Japanese Orthopaedic Association scale in patients with degenerative cervical myelopathy. Spine (Phila Pa 1976) 2015;40:1653-9.

14. Sielatycki JA, Chotai S, Kay H, Stonko D, McGirt M, Devin CJ. Does obesity correlate with worse patientreported outcomes following elective anterior cervical discectomy and fusion? Neurosurgery 2016;79:6974.

15. Tian L, Yang R, Wei L, et al. Prevalence of osteoporosis and related lifestyle and metabolic factors of postmenopausal women and elderly men: a crosssectional study in Gansu province, Northwestern of China. Medicine (Baltimore) 2017;96:e8294.
16. Pan WH, Flegal KM, Chang HY, Yeh WT, Yeh CJ, Lee WC. Body mass index and obesity-related metabolic disorders in Taiwanese and US whites and blacks: implications for definitions of overweight and obesity for Asians. Am J Clin Nutr 2004;79:31-9.

17. Webb R, Brammah T, Lunt M, Urwin M, Allison T, Symmons D. Prevalence and predictors of intense, chronic, and disabling neck and back pain in the UK general population. Spine (Phila Pa 1976) 2003;28:1195-202.

18. Seicean A, Alan N, Seicean S, et al. Impact of increased body mass index on outcomes of elective spinal surgery. Spine (Phila Pa 1976) 2014;39:1520-30.

19. Schoenfeld AJ, Carey PA, Cleveland AW 3rd, Bader JO, Bono CM. Patient factors, comorbidities, and surgical characteristics that increase mortality and complication risk after spinal arthrodesis: a prognostic study based on 5,887 patients. Spine J 2013;13:11719.

20. Buerba RA, Fu MC, Grauer JN. Anterior and posterior cervical fusion in patients with high body mass index are not associated with greater complications. Spine J 2014;14:1643-53. 